\title{
Study on Soil Mobility of Two Neonicotinoid Insecticides
}

\author{
Mária Mörtl, ${ }^{1}$ Orsolya Kereki, ${ }^{2}$ Béla Darvas, ${ }^{1}$ Szandra Klátyik, ${ }^{1}$ Ágnes Vehovszky, ${ }^{3}$ \\ János Györi, ${ }^{3}$ and András Székács ${ }^{1}$ \\ ${ }^{1}$ Agro-Environmental Research Institute, National Agricultural Research and Innovation Centre, Herman O. Utca 15, \\ Budapest 1022, Hungary \\ ${ }^{2}$ Faculty of Chemical Technology and Biotechnology, Budapest University of Technology and Economics, Budapest 1111, Hungary \\ ${ }^{3}$ Balaton Limnological Institute, Centre for Ecological Research, Hungarian Academy of Sciences, P.O. Box 35, Tihany 8237, Hungary
}

Correspondence should be addressed to András Székács; a.szekacs@cfri.hu

Received 31 January 2016; Revised 5 May 2016; Accepted 8 May 2016

Academic Editor: Eulogio J. Llorent-Martinez

Copyright (C) 2016 Mária Mörtl et al. This is an open access article distributed under the Creative Commons Attribution License, which permits unrestricted use, distribution, and reproduction in any medium, provided the original work is properly cited.

\begin{abstract}
Movement of two neonicotinoid insecticide active ingredients, clothianidin (CLO) and thiamethoxam (TMX), was investigated in different soil types (sand, clay, or loam) and in pumice. Elution profiles were determined to explore differences in binding capacity. Soil characterized by high organic matter content retained the ingredients, whereas high clay content resulted in long release of compounds. Decrease in concentration was strongly influenced by soil types: both CLO and TMX were retained in loam and clay soils and showed ready elution through sandy soil and pumice. Elution capability of the active ingredients in sandy soil correlated with their water solubility, indicating approximately $30 \%$ higher rapidity for TMX than for CLO. Soil organic carbonwater partitioning coefficients $\left(K_{\mathrm{oc}}\right)$ determined were in good agreement with literature values with somewhat lower value for CLO in sandy soil and substantially higher values for TMX in clay soil. High mobility of these neonicotinoid active ingredients in given soil types urges stronger precautionary approach taken during their application.
\end{abstract}

\section{Introduction}

Since the introduction of the first neonicotinoid insecticide (imidacloprid) in 1991, neonicotinoids became the most widely used systemic insecticides. Their share in the global market for insecticides was $27 \%$ in 2010 [1], $28.5 \%$ in 2011 [2], and $16.7 \%$ in 2013 [3] and was estimated to be $16.4 \%$ in 2015 [4]. Moreover, the compound annual growth rate of neonicotinoids is forecasted to be $4.2 \%$ between 2014 and 2019; therefore, neonicotinoid sales are expected to grow to reach 2650 million USD, by 2019 [3]. This reflects a predicted gradual decline in the share of neonicotinoids in the overall insecticide market (16.1\% in 2019), in spite of the ongoing market growth, as their compound annual growth rate does not appear to keep up with that of all insecticides. It is alarming, however, that the growth rate of organophosphate insecticides remains above the average growth rate of the entire insecticide market. The vast majority of the neonicotinoid active ingredients are used as seed coating, despite the fact that their prophylactic application cannot be considered in integrated pest management approaches, and studies from across the US and UK indicated no consistent yield benefits of neonicotinoid seed treatments under typical pest pressure $[5,6]$. Except for organic farming nearly all of maize seeds planted in North America are coated with neonicotinoids, mainly with clothianidin (CLO) or thiamethoxam (TMX). They are also routinely applied in developing countries and noncoated seeds are often unavailable for purchase [7]. In Ghana they are currently applied on cocoa farms usually four times in a year at no cost to farmers under a government subsidized national spraying program [8]. The current use of these systemic pesticides is not sustainable globally [9]. Neonicotinoids appear as ubiquitous pollutants in the environment, and especially surface water resources are compromised. According to a recent study [10] at least one neonicotinoid was detected in $63 \%$ of the 48 streams in the US sampled, indicating the rate of exposure of nontarget species. Evolution of insecticide-resistance of insect pests in field populations was also reported [11, 12]. Further unintended 
consequences of overusing insecticides might involve resurgence of target pests as well as outbreaks of nontarget pests [5]. There exist certain alternative agroecological techniques in crop production to reduce neonicotinoid application, for example, crop rotation, altering tillage and irrigation timing, and prediction of peak pest attack by monitoring population levels [9]. Nonetheless, pheromone use only controls Lepidopteran and Dipteran insect, and economic threshold levels are very difficult to be maintained by them. In addition, alternative agronomic strategies are not being applied on a wide scale, and the use of crop- and region-specific decisionsupport tools for neonicotinoid use is surprisingly scarce [5].

Neonicotinoids are persistent in soils under appropriate conditions. Among others low levels in soil quality, in microbial activity, in temperature, and in precipitation increase the dissipation time. Their reported half-lives $\left(\mathrm{DT}_{50}\right)$ vary by compound and environmental circumstances, but range is 150-6900 days for CLO and 35-3000 days for TMX [6].

Cases of severe bee poisoning and updated risk assessment by EFSA in January 2013 led EU Commission to the conclusion [13] that a high risk for bees cannot be excluded except by imposing further restrictions involving withdrawal of authorization of neonicotinoids and ban of coated seeds for different crops. The restriction applies to the use of 3 neonicotinoids (CLO, imidacloprid, and TMX) for seed treatment, soil application (granules), and foliar treatment on crops attractive to bees, including certain cereals. From an ecotoxicological aspect it is essential that the restriction in the use of neonicotinoids should not be compensated by increased use of organophosphates, particularly chlorpyrifos. Reassessment of these neonicotinoids was scheduled by the EU Commission to be executed by the end of 2015. The corresponding scientific report was published in 2015 [14], facilitating risk managing authorities to come to a decision on this regulatory question of high importance.

For the analysis of neonicotinoids liquid chromatographic methods [15] are generally used, although immunoanalytical $[16,17]$ and gas chromatographic methods (GC) were also reported. Due to heat sensitivity of some of these target compounds, derivatization and/or complicated sample pretreatment are required prior to GC measurements. For example, imidacloprid was hydrolyzed under basic conditions at $85^{\circ} \mathrm{C}$ prior to its GC determination [18]; then the aqueous solution was neutralized, the target compound was extracted twice by chloroform, and the combined organic solution was dried with anhydrous sodium sulfate, filtered, and concentrated. The hydrolysis product was amenable to GC and it was detected by mass spectrometry using selected ion monitoring mode. In addition, electron capture detection (ECD) following GC separation was applied for determination of TMX [19] and CLO [20, 21]. High performance liquid chromatographic (HPLC) applications are preferred especially for aqueous samples, as removal of water (i.e., extraction of target compounds with an organic solvent) and/or chemical transformation can be omitted prior to measurement. For detection of neonicotinoids UV [22], diode array detector (DAD) $[23,24]$ or mass spectrometry $[25,26]$ are suitable. Determination of these ingredients from complex matrices (e.g., foods) requires more complicated sample preparation, as the coextracted substances often interfere with target compounds; thus clean-up cannot be omitted and selective detection mode (e.g., LCMS/MS) is necessary. For the extraction of imidacloprid from soil polar solvents (water, methanol, and acetonitrile) have been applied [15]. In the case of TMX microwave assisted extraction and water as solvent [27] have been used for the extraction of residues from vegetable and soil samples. Clean-up of extracts has been performed by hexane partitioning (this fraction was discarded) or by solid phase extraction cartridges containing Lichrolut RP-18 phase (Merck). Ultrasonication-facilitated sample preparation without clean-up has been effectively used for extraction of CLO with ethyl acetate followed by salting out using sodium chloride [20] and aqueous extraction of TMX [28].

The aim of this work was to study the mobility of two neonicotinoid active ingredients currently restricted from use by the EU [13], CLO, and TMX. The fate of these two active ingredients appeared to be expedient to be studied in parallel, as the compounds are related to each CLO being a metabolite of TMX. Elution characteristics of CLO and TMX in different soil types were studied. In order to determine the amount of insecticide residues in soil, a reliable sample preparation method based on the QuEChERS methodology [29] has been optimized.

\section{Materials and Methods}

2.1. Materials. CLO and TMX analytical standards were purchased from Fluka (purity 99.9\% for CLO and 99.6\% for TMX, Pestanal). Methanol was of HPLC grade (Fisher Chemical) and water was provided by Aqua MAX-Ultra (YL Instrument Co. Ltd., Korea) water purification system.

For investigation of the absorption of neonicotinoids in soils $1.20 \mathrm{~g}$ TMX (prepared from $5 \mathrm{~mL}$ of Actara 240 SC, Syngenta) and $1.03 \mathrm{~g}$ CLO (prepared from $2.06 \mathrm{~g}$ Apache 50 WG, Sumitomo Chemical) were dissolved in 2.0 liters of water. Thus, stock solution contained CLO and TMX at concentration of $2.06 \mathrm{mM}$. For soil adsorption experiments, this stock solution was diluted 250 -fold $(8.24 \mu \mathrm{M})$, that is, approximately one-tenth of lower dose recommended by the manufacturer (10-40 mL Actara 240 SC spraying agent to 100 liters of water).

Three different soil types (sand, clay, and loam) and pumice have been used as media for growing the maize plants. Sandy soil from Örbottyán (Hungary) consisted of $90.8 \%$ sand, $4.8 \%$ silt, and $4.4 \%$ clay and was characterized by low organic matter content $(0.52 \%)$. Loam, purchased in local gardening shop as a potting soil for general purposes with over $40 \%$ organic matter, contained $39.4 \%$ sand, $40.3 \%$ silt, and $20.3 \%$ clay. The third soil (clay) originated from Budapest (Hungary) and it was characterized by $12.7 \%$ sand, $55.5 \%$ silt, and $31.8 \%$ clay content and $2.15 \%$ of organic matter. Pumice (vitro-clastic perlite, $1-2 \mathrm{~mm}$ ) was purchased from Perlifert Ltd. (Hungary). This amorphous ground rock mined in North-Eastern Hungary loses $6.26 \%$ of its mass upon heating, and the residue consists of $73.04 \% \mathrm{SiO}_{2}, 13.34 \%$ $\mathrm{Al}_{2} \mathrm{O}_{3}, 5.35 \% \mathrm{~K}_{2} \mathrm{O}$, and $1.23 \% \mathrm{Fe}_{2} \mathrm{O}_{3}$. 
TABLE 1: Recoveries in the modified QuEChERS method at three concentrations.

\begin{tabular}{|c|c|c|c|c|c|c|c|c|}
\hline \multirow{2}{*}{$\begin{array}{l}\text { Conc. in soil } \\
\mu \mathrm{g} / \mathrm{g}\end{array}$} & \multicolumn{2}{|c|}{ Clay soil samples } & \multicolumn{2}{|c|}{ Loam soil samples } & \multicolumn{2}{|c|}{ Sand soil samples } & \multicolumn{2}{|c|}{ Pumice } \\
\hline & CLO & TMX & $\mathrm{CLO}$ & TMX & CLO & TMX & $\mathrm{CLO}$ & TMX \\
\hline 0.02 & $69.4 \pm 10.2$ & $83.2 \pm 6.3$ & $61.3 \pm 17.5$ & $48.3 \pm 17.3$ & $91.8 \pm 7.0$ & $100.8 \pm 5.9$ & $92.4 \pm 9.1$ & $98.8 \pm 7.4$ \\
\hline 0.10 & $97.1 \pm 2.0$ & $91.3 \pm 2.6$ & $90.1 \pm 8.5$ & $87.8 \pm 2.8$ & $100.5 \pm 3.5$ & $99.4 \pm 1.2$ & $101.4 \pm 5.4$ & $98.7 \pm 4.1$ \\
\hline 1.0 & $100.6 \pm 9.3$ & $99.5 \pm 8.5$ & $99.7 \pm 2.6$ & $97.2 \pm 3.0$ & $100.7 \pm 2.2$ & $102.3 \pm 1.1$ & $103.1 \pm 3.5$ & $101.5 \pm 3.6$ \\
\hline
\end{tabular}

$n=3$; extractions were carried out in triplicate.

2.2. HPLC Analysis. Analyses of samples were performed on Younglin YL9100 HPLC system equipped with a YL9150 autosampler. Compounds were generally separated on a $\mathrm{C} 18$ column $(150 \mathrm{~mm} \times 4.6 \mathrm{~mm}$ i.d., $5 \mu \mathrm{m})$ at $40^{\circ} \mathrm{C}$. A column manufactured by Today Science Ltd. (Budapest, Hungary) was filled with SP-120-5-ODS-AP grade Daisogel (Osaka, Japan) phase. UV detector signals were recorded at $\lambda=$ $269 \mathrm{~nm}$ for CLO and $\lambda=252 \mathrm{~nm}$ for TMX and used for quantification. External calibration was based on the results obtained for 12 standard solutions in the range of concentrations between $10 \mathrm{ng} / \mathrm{mL}$ and $150 \mu \mathrm{g} / \mathrm{mL}$. Calibration solutions were prepared from a stock solution by dilution with water. Dilution with methanol resulted in broad signals or duplication of peaks at higher concentrations. Eluent flow rate was $1.0 \mathrm{~mL} / \mathrm{min}$ with isocratic elution for 5 minutes $(70: 30=\mathrm{A}: \mathrm{B}$ eluents, $\mathrm{A}=90 \%$ water $: 10 \% \mathrm{MeOH}, \mathrm{B}=$ $\mathrm{MeOH}$ ), followed by a linear gradient (to reach $100 \% \mathrm{MeOH}$ at $8 \mathrm{~min}$, held for $3 \mathrm{~min}$ ) at the end to remove noneluting compounds. Retention times were 3.17 and $4.65 \mathrm{~min}$ for TMX and CLO, respectively. In some cases separation of the analytes was achieved on an Agilent Extend-C18 column (150 $\mathrm{mm} \times$ $4.6 \mathrm{~mm}$ i.d., $5 \mu \mathrm{m}$ ) equipped with an Agilent Guard column $(12.5 \mathrm{~mm} \times 4.6 \mathrm{~mm}$ i.d., $5 \mu \mathrm{m})$. Retention times were in these cases 2.42 and $3.38 \mathrm{~min}$ for TMX and CLO, respectively. Limits of detection (LODs), defined as analyte concentrations corresponding to a signal level of signal/noise ratio of 3 , were determined with standard solutions. LOD values lied at $10 \mathrm{ng} / \mathrm{mL}$ for TMX and approximately $8 \mathrm{ng} / \mathrm{mL}$ for CLO.

2.3. Adsorption/Elution of Neonicotinoids in Soil. The time required to reach partition equilibrium of neonicotinoids between soil samples and water was examined by adding $200 \mathrm{~mL}$ of aqueous solutions containing equal molar quantities $\left(1.65 \cdot 10^{-6} \mathrm{~mol}\right)$ of TMX and CLO to $10 \mathrm{~g}$ of soil. The samples were then stirred and after different time periods (10 min, 4, 8, 24, and $72 \mathrm{~h}$ ) both soil and liquid phases where analyzed.

The movement of TMX and CLO through a soil column was studied according to the procedure described for imidacloprid [30]. The elution profile can provide important information on the leaching behavior of an insecticide in different soil types. The neonicotinoid content of the leachates obtained by elution of the active ingredients from different soil columns (clay, loam, or sand soils) was determined for TMX and CLO. Soils have been previously dried overnight on air and were filled into a chromatographic glass column (height: $180 \mathrm{~mm}$, internal diameter: $40 \mathrm{~mm}$ ). Masses fitting the column were $191.36 \mathrm{~g}, 262.71 \mathrm{~g}, 150.50 \mathrm{~g}$, and $139.87 \mathrm{~g}$ for clay, sand, and loam soil and pumice, respectively. Portions of the stock solution diluted 250 -fold (see Section 2.1.) were applied. Thus, equal molar quantities $\left(8.24 \cdot 10^{-7} \mathrm{~mol}\right)$ of CLO and TMX were loaded in $10 \mathrm{~mL}$ solution onto the columns, which were then washed with successive $10 \mathrm{~mL}$ volumes of water. As each $10 \mathrm{~mL}$ wash was added to the top of the column, $10 \mathrm{~mL}$ (the eluate) was displaced at the bottom. The first eluate occurred after $80,70,30$, and $30 \mathrm{~mL}$ of water had been added on the top of the column for clay, sand, loam, and pumice, respectively. The insecticide contents in each eluate, as well as the residues in soil, were quantified by HPLC. After elution, the soil phases were divided into two equal parts (upper and lower layers), and neonicotinoids were extracted according to the optimized sample preparation procedure (see Section 2.4).

2.4. Extraction of Neonicotinoids from Soil Samples. For the extraction of target compounds from different soil types several polar extraction solvents were tested, for example, water, acetone, and acetonitrile. In contrast to water and acetone, extraction with acetonitrile, using the well-established QuEChERS procedure [29], resulted in high recoveries, although with observable consequences in the analytical determination in clay (see Table 1), for example, matrix interferences and peak tailing in HPLC. As chromatographic separation occurred in methanol-water eluents, the presence of acetonitrile as an eluent in the mobile phase deteriorates peak shapes. Such peak broadening and tailing occurred if the organic solvent (e.g., acetonitrile) differed from the HPLC eluent (methanol: water) and could be avoided by solvent exchange. Thus, slight modification of the original QuEChERS method by insertion of a solvent exchange step was required. The improved procedure was carried out, as follows: soil samples were treated with $1.0 \mathrm{~mL}$ of spike solution containing $10 \mu \mathrm{g}$ of both neonicotinoids (at $1.0 \mu \mathrm{g} / \mathrm{g}$ concentration) in water and left to dry overnight. Blank samples were also extracted in all cases, with citrate salts used as buffering medium in the salting out step, as it appears to be the most commonly reported in literature for soil matrix. To $10 \mathrm{~g}$ of air-dried soil sample, $14 \mathrm{~mL}$ of acetonitrile, and $6 \mathrm{~mL}$ of water were added in a $50 \mathrm{~mL}$ centrifuge tube, and the tube was vigorously shaken for $1 \mathrm{~min}$, followed by ultrasound agitation for $10 \mathrm{~min}$ and by centrifugation at $3000 \mathrm{rpm}$ for $10 \mathrm{~min}$. To the sample $6.0 \mathrm{~g}$ of $\mathrm{MgSO}_{4}, 1.5 \mathrm{~g}$ of NaCl, $1.5 \mathrm{~g}$ of trisodium citrate dihydrate, and $0.75 \mathrm{~g}$ of sodium hydrogen citrate sesquihydrate were added, the mixture was manually shaken for $1 \mathrm{~min}$, and then ultrasound agitation for $5 \mathrm{~min}$ and centrifugation for $10 \mathrm{~min}$ 

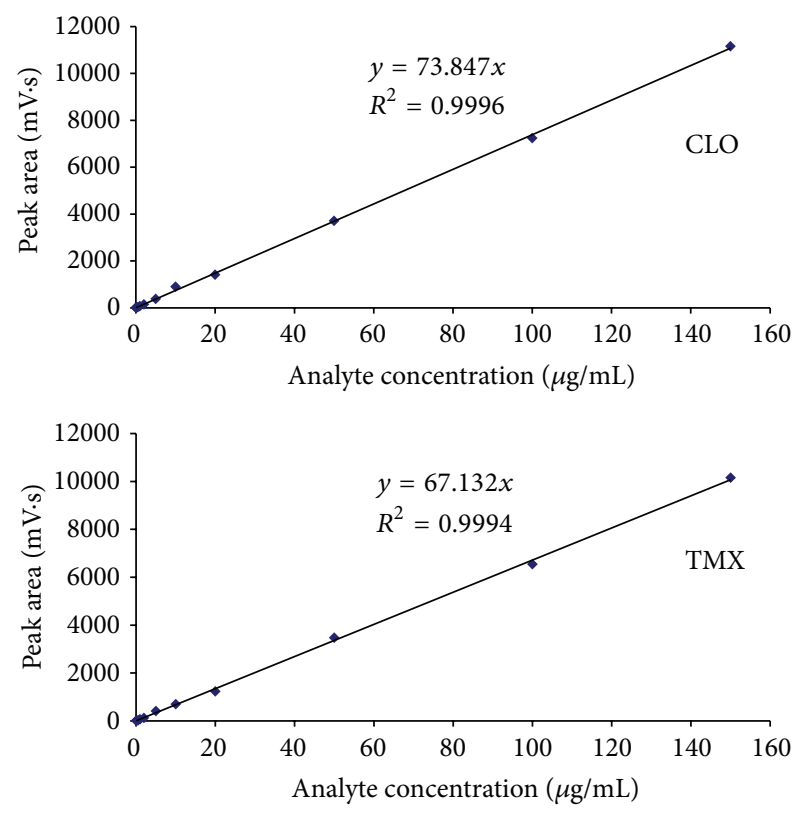

FIgure 1: Calibration curves for CLO and TMX determined at $269 \mathrm{~nm}$ and at $252 \mathrm{~nm}$, respectively.

were performed. Into a $15 \mathrm{~mL}$ centrifuge tube $8 \mathrm{~mL}$ of the supernatant was added, and clean-up was carried out by $270 \mathrm{mg}$ primary secondary amine (PSA), $800 \mathrm{mg} \mathrm{MgSO}_{4}$, and $270 \mathrm{mg} \mathrm{C} 18$ dispersive phases. The sample was then homogenized with vortex and centrifuged at $3000 \mathrm{rpm}$ for $10 \mathrm{~min}$. Five $\mathrm{mL}$ of the supernatant was evaporated to dryness in a $10 \mathrm{~mL}$ test tube under $\mathrm{N}_{2}$ stream. The residue was then dissolved in $1 \mathrm{~mL}$ of methanol/water mixture (3:7), homogenized with vortex, then filtered through a $0.45 \mu \mathrm{m}$ polytetrafluoroethylene syringe filter prior to HPLC analysis. Thus, final concentration of the extract was $2.5 \mu \mathrm{g} / \mathrm{mL}$ in principle. Experiments were carried out also at fortification levels of $0.10 \mu \mathrm{g} / \mathrm{g}$ and $0.02 \mu \mathrm{g} / \mathrm{g}$ in three replicates of each.

\section{Results}

3.1. Calibration of Quantitative Determination of CLO and TMX. Both analytes were determined from HPLC peak areas at the corresponding retention times with excellent linear calibration characteristics (calibration curves shown in Figure 1). Thus, for quantification of target compounds, peak areas determined for CLO at $269 \mathrm{~nm}$ and for TMX at $252 \mathrm{~nm}$ were used. The linear regression values of external calibration curves were 0.9996 and 0.9994 , and the slopes were 73.85 and 67.13 for CLO and TMX, respectively. Peak purity was checked by ratios of signal intensities (peak areas) recorded at $252 \mathrm{~nm}$ and at $269 \mathrm{~nm}$. These values for standard solutions were 1.685 and 0.809 for TMX and CLO, respectively. Relative standard deviations established for different concentration levels for three parallel injections were between $0.71 \%$ and $1.86 \%$.

3.2. Extraction of Soil Samples. Water, acetone, and acetonitrile were tested as soil extraction solvents. Recoveries lied
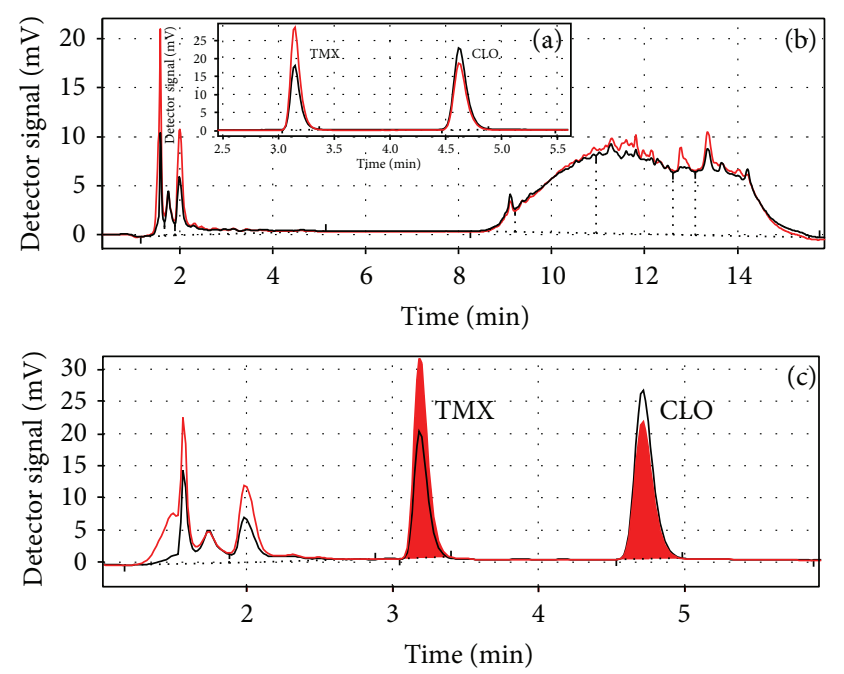

FIGURE 2: Chromatograms of a standard solution of CLO and TMX at $2.50 \mu \mathrm{g} / \mathrm{mL}$ (a), a blank clay sample (b), and the same clay sample spiked with CLO and TMX at $1.0 \mu \mathrm{g} / \mathrm{g}$ (c). Chromatograms were recorded at $269 \mathrm{~nm}$ (Channel 1, black line) and at $252 \mathrm{~nm}$ (Channel 2, red line). Retention times were 3.17 and $4.65 \mathrm{~min}$ for TMX and CLO, respectively.

around $60 \%$ for clay samples with water, whereas in extracts of loam samples, target compounds could not be detected. Extraction with acetone resulted in similar recoveries for clay samples; however, target compounds appeared in the extracts of loam soils with low recoveries (CLO 13\%, TMX 21\%). The QuEChERS method using a mixture of acetonitrile and water gave high recoveries for both soil types, but with distorted peak shapes (tailing) leading to calculated recoveries vastly exceeding 100\% (CLO 128\%, TMX 126\%) from clay soils and somewhat lower levels from loam (CLO 107\%, TMX 83\%). Deterioration of peak symmetry (tailing) disturbing recovery calculation is due to the presence of acetonitrile in HPLC analysis of the soil extract with the methanol-water chromatography eluent. Therefore, modification of the QuEChERS method by removal of acetonitrile and solvent exchange to methanol-water was essential. Under the soil extraction procedure conditions, extraction of spiked soil samples at levels $1.0,0.1$, and $0.02 \mu \mathrm{g} / \mathrm{g}$ resulted in nominal concentrations in the final extracts of 2500,250 , and $50 \mathrm{ng} / \mathrm{mL}$ of the target analytes, respectively. Recoveries obtained in this completed QuEChERS method are summarized in Table 1 and chromatograms for blank, standards, and spiked clay soil samples prepared by this method are shown in Figure 2 .

3.3. Adsorption/Elution of Neonicotinoids in Soil. The partition equilibrium for neonicotinoids between soil particles and water when being washed into the soil occurred fast, and partition coefficients were in accordance with the water solubility of the target analytes and their adsorptivity on soils: experiments showed that the equilibrium emerged within $10 \mathrm{~min}$; thereafter, there occurred no significant changes in the amount of TMX and CLO adsorbed to the surface of the soil phase. Mass ratios of the dissolved (aqueous solution) 


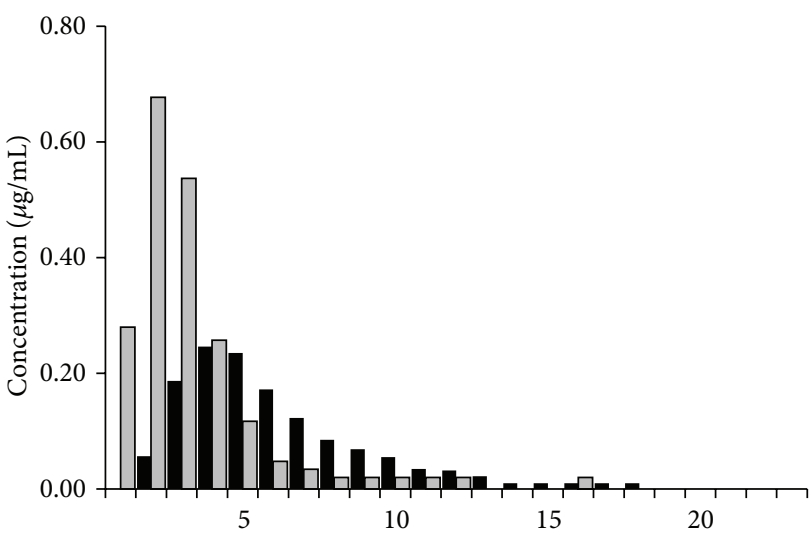

Fraction number

(a)

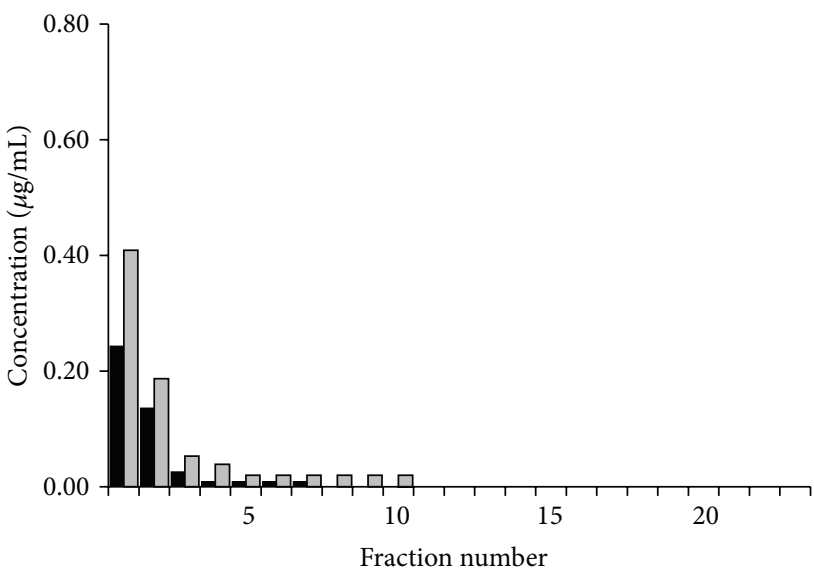

(c)

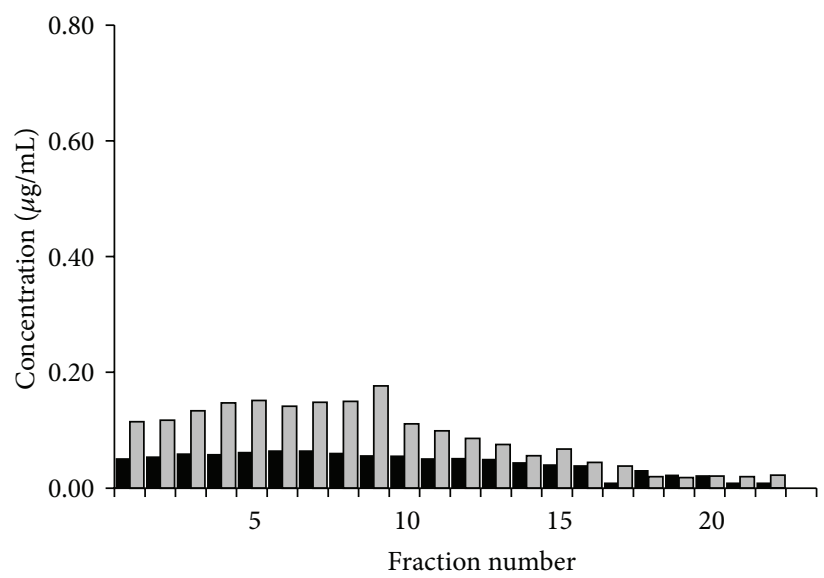

(b)

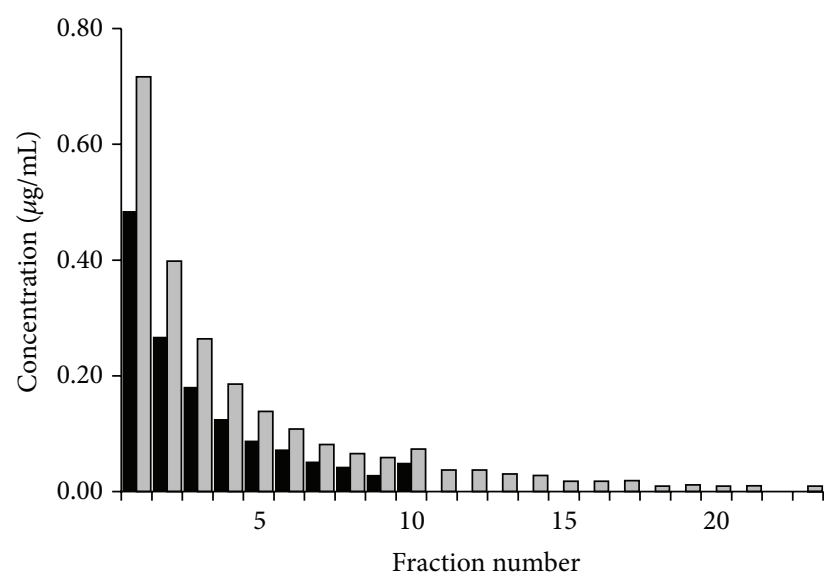

(d)

FIgURE 3: Elution profiles of CLO and TMX upon absorption on soils. Concentrations of CLO (black columns) and TMX (grey columns) measured in aqueous eluates from soil columns of sand (a), clay (b), and loam (c) soils. Eluates from pumice columns (d) are shown as control. Concentrations in $10 \mathrm{~mL}$ fractions of the eluate are shown in $\mu \mathrm{g} / \mathrm{mL}$, as a function of the fraction number.

TABLE 2: Soil organic carbon-water partitioning coefficients $\left(K_{\mathrm{oc}}\right)$ obtained for CLO and TMX.

\begin{tabular}{lccccc}
\hline \multicolumn{5}{c}{$K_{\text {oc }}(\mathrm{mL} /$ g o.c. $)$} \\
& Soil type & & \\
& Sand & Clay & Loam & Reference value & Cited \\
\hline CLO & 106.1 & 153.9 & 159.9 & $160(84-345)$ & {$[35,38]$} \\
TMX & 54.4 & 106.2 & 60.4 & $68.4(32.5-237)$ & {$[35]$} \\
\hline
\end{tabular}

${ }^{\mathrm{a}}$ Mean values; ranges are shown in parentheses.

and adsorbed (soil) portions of CLO were 65.5, 10.4, and 0.54 for sand, clay, and loam, respectively. In accordance with its higher water solubility, the corresponding ratios were 122 , 15.1, and 1.43 for TMX, respectively. Soil organic carbon-water partitioning coefficients $\left(K_{\mathrm{oc}}\right)$ obtained are summarized in Table 2.

The effect of soil types on the movement of CLO and TMX in soil was investigated in a soil column experiment. Elution profiles (Figure 3) varied by soil types studied. Poor binding potential of sandy soil probably accounted for high levels of neonicotinoids detected in the first 5th-6th eluates under the high irrigation load applied (Figure 3(a)). In accordance with its better water solubility, TMX occurred in the eluate earlier than CLO, and its maximum concentration of TMX $(0.677 \mu \mathrm{g} / \mathrm{mL})$ was higher than that of CLO $(0.246 \mu \mathrm{g} / \mathrm{mL})$. The eluted concentrations gradually decreased in further fractions for both compounds. High clay content soil showed a greater capacity to bind both TMX and CLO, reflected in their retarded downward movement, continuous leaching, and long dissipation (Figure 3(b)). Loam displayed an even stronger retention of both compounds, possibly due to its high organic matter content compared to the two other soil types. Although high concentrations (peak concentration $0.41 \mu \mathrm{g} / \mathrm{mL}$ for TMX and $0.24 \mu \mathrm{g} / \mathrm{mL}$ for CLO) of the compounds occurred in the first two fractions, probably due to the so-called vadose zone processes and consequent preferential flow (rapid partial passage through soil cracks and pores), the amount of such by-passing ingredients diminished very quickly (Figure 3(c)), and considerable amounts of both insecticides remained in the soil. In accordance with our expectations, soil residual level for both compounds was the highest for loam soil and lowest for sandy soil (Table 3). 
TABLE 3: Residues of CLO and TMX in soil columns. Residues of neonicotinoids absorbed on the soil and pumice columns. Residual levels were separately determined in the upper and lower half segments of the columns after preparation of samples by QuEChERS method.

\begin{tabular}{lcccccrr}
\hline $\begin{array}{l}\text { Conc. in extract } \\
\mu \mathrm{g} / \mathrm{mL}\end{array}$ & \multicolumn{2}{c}{ Clay soil samples } & \multicolumn{2}{c}{ Loam soil samples } & \multicolumn{2}{c}{ Sand soil samples } & \multicolumn{2}{c}{ Pumice } \\
\hline $\begin{array}{l}\text { Upper half } \\
\text { segment }\end{array}$ & CLO & TMX & CLO & TMX & CLO & TMX & CLO \\
$\begin{array}{l}\text { Lower half } \\
\text { segment }\end{array}$ & 0.089 & $\sim 0.010$ & 0.352 & 0.299 & $\sim 0.010$ & $<0.010$ & $\sim 0.010$ \\
\hline
\end{tabular}

Pumice showed a very low binding capacity towards the active ingredients studied. Concentrations in the first fraction reached the highest values and then gradually decreased (Figure 3(d)). TMX was detected even in the last eluate fractions and was hardly detected as residue above the LOD in the solid phase. According to water solubility data, concentrations measured for TMX were generally higher than that for CLO. Masses of eluted TMX compared to loaded amounts were $86 \%, 82 \%, 34 \%$, and $99 \%$ for sand, clay, loam, and pumice. Corresponding levels for CLO were 66\%, 48\%, $22 \%$, and $68 \%$, respectively. The overall molar ratios of the eluted TMX related to CLO lied at 1.11, 1.46, 1.33, and 1.26 for sand, clay, loam, and pumice, indicating the higher mobility of TMX than CLO in all cases. Ratios in eluates were the most variable for sand and the least for pumice. Results are in accordance with binding capacity of soils and with higher water solubility of TMX.

\section{Discussion}

Solid-liquid extraction and partitioning at low temperature were also proposed prior to GC-ECD determination of TMX in soil [19]. The optimized procedure reported involved extraction with a mixture of acetonitrile and ethyl acetate, freezing, and drying. The method allowed a limit of detection of $0.006 \mathrm{mg} / \mathrm{kg}$ and $96 \%$ recovery. Recently application of the QuEChERS extraction procedure prior to LCMS/MS analysis of soil samples from cocoa plantations has been reported [8], applying a desalting analyte extraction step with $\mathrm{NaCl}$ and $\mathrm{MgSO}_{4}$ in acidified acetonitrile, followed by clean-up with PSA. Recoveries were found to be $97 \%$ for TMX and $103 \%$ for CLO. Recoveries reported for all neonicotinoids studied were highest with PSA (with the exception of TMX) and appeared to decrease upon the addition of C-18 and graphitized carbon black (GCB) sorbent. A similar procedure has been used prior to LC-ESI-MS/MS analysis of soil grab samples collected from maize fields in Canada [31]. CLO and TMX were extracted by acetonitrile containing $\mathrm{MgSO}_{4}, \mathrm{NaCl}$, and citrate buffer, but solid phase extraction (clean-up) was not applied.

The QuEChERS sample preparation procedure used in our study proved to be suitable method for extraction of TMX and CLO from soils. Recoveries were similar to those reported recently [8]. Our results determined at three different levels showed lower recoveries (48.3 to $83.2 \%$ ) at low level $(0.02 \mu \mathrm{g} / \mathrm{g}$ in soil) for clay and loam soils, whereas high recoveries ( 91.8 to $100.8 \%$ ) were obtained even at low level in sandy soil and pumice of low binding capacity. Remarkable differences in recoveries in aqueous extraction from various soil types indicate that the rate of leaching may substantially vary even for these water soluble ingredients.

Regarding the elution profiles, CLO and TMX can be considered as highly mobile and susceptible to leaching in sandy soil, but they are only moderately mobile in loam. Our results are in accordance with those reported for the transport of imidacloprid [32] that exhibited high mobility in silty kaolinite-type soil, whereas limited mobility was found in soil with high organic matter content. Recoveries in effluent solution were significantly lower $(27 \%)$ in the latter case compared to $69 \%$ obtained for silty soil. Similarly slow release of imidacloprid was observed for vineyard soils with higher clay content [30]. The effect of soil types on the movement of imidacloprid in different soil columns has been studied earlier by determination of elution profiles [30], and soils of higher clay content and increased binding capacity retarded the movement of this compound. Thus, holding the insecticide in the upper layers of the soil, it could be solubilized during irrigation and thus made available to the roots for uptake.

Despite their high mobility in soil, neonicotinoids have accumulative characteristics. Dissipation rates among other factors are influenced by sorption to soil particles and by soil moisture. Regarding TMX, the equivalent of $65 \mathrm{~cm}$ rainfall caused leaching of $66-79 \%$ of the active ingredient [33] from a sandy soil column. As for dissipation of TMX longer persistence was observed under dry conditions $\left(t_{1 / 2} 200.7-\right.$ 301.0 days) than in more humid cases [33]. It is worthy to note that, due to their large-scale use, neonicotinoids are widely detected in arable soils [7, 31]. Thus, transport pattern of these agrochemicals and the environmental risk of potential leaching to groundwater supplies are strongly influenced by soil type in addition to intensity of rain events or irrigation.

The chemical mobility of chemical substances in soil can be assessed on the basis of liquid chromatographic retention parameters and soil thin layer chromatography (sTLC) or in soil column leaching experiments. Retention times observed in reverse phase HPLC, which correlate with solubility characteristics and octanol/water partition coefficients, are a vague descriptor of substance mobility in soil as well. TMX is 12-13.5-fold more soluble in water and 1.5fold less soluble in octanol than CLO, and the same trend of hydrophilic and lipophilic characteristics is seen in the octanol-water partition coefficients $\left(\log P_{\text {ow }}=-\log K_{\text {ow }}\right)$ of the two compounds, indicating TMX to be 6.8-fold more hydrophilic than CLO (see Table 4). Nonetheless, substance mobility in soil is strongly affected, besides physicochemical parameters (e.g., solubility features) of the given compounds, also by soil characteristics. To assess the effect of soil type 
TABLE 4: Physicochemical constants of CLO and TMX [35, 40-42].

\begin{tabular}{|c|c|c|c|c|c|}
\hline & \multicolumn{2}{|c|}{ Solubility } & \multirow{2}{*}{$\log P^{\mathrm{a}}$} & \multicolumn{2}{|c|}{$\mathrm{DT}_{50}$} \\
\hline & Water (g/L) & Octanol (g/L) & & Water (day) & Soil (day) \\
\hline CLO & $0.327^{\mathrm{b}}\left(0.304^{\mathrm{c}}, 0.34^{\mathrm{d}}\right)$ & $0.938^{\mathrm{a}}$ & $0.732^{\mathrm{f}}(0.893-0.905)^{\mathrm{g}}$ & $1401^{\mathrm{i}}$ & $143-1001^{1}$ \\
\hline TMX & $4.1^{\mathrm{e}}$ & $0.62^{\mathrm{a}}$ & $-0.13^{\mathrm{h}}$ & $\begin{array}{l}640^{\mathrm{j}} \\
8.4^{\mathrm{k}}\end{array}$ & $32.3(7-109)^{\mathrm{m}}$ \\
\hline
\end{tabular}

${ }^{\mathrm{a}} 25^{\circ} \mathrm{C} ;{ }^{\mathrm{b}} 20^{\circ} \mathrm{C} ;{ }^{\mathrm{c}}$ at $20^{\circ} \mathrm{C}$ and $\mathrm{pH} 4 ;{ }^{\mathrm{d}}$ at $20^{\circ} \mathrm{C}$ and $\mathrm{pH} 10 ;{ }^{\mathrm{e}}$ at $25^{\circ} \mathrm{C}$ and $\mathrm{pH} 7.3 ;{ }^{\mathrm{f}} \mathrm{pH}$ not specified; ${ }^{\mathrm{g}} 0.893,0.905$, and 0.873 at $\mathrm{pH} 4$, $\mathrm{pH} 7$, and $\mathrm{pH} 10$, respectively;

${ }_{\mathrm{pH}} 6.8$ and/or not specified; ${ }^{\mathrm{i}}$ at $20^{\circ} \mathrm{C}$ and pH 9; ${ }^{\mathrm{j}}$ at $25^{\circ} \mathrm{C}$ and pH $7{ }^{\mathrm{k}} 25^{\circ} \mathrm{C}$ and pH 9; ${ }^{1}$ under aerobic laboratory conditions; ${ }^{\mathrm{m}}$ under field conditions ( 37 soils).

on substance mobility, sTLC methods have been established and were proven to be reliable for predicting movement of chemicals [34], although the utility of the method to predict actual pesticide movement in field applications is admittedly limited due to the high variability in soil structure and occurrent field conditions. Determination of the $R_{f}$ values in sTLC is performed in a soil layer formed on a glass plate by applying a soil slurry, dried subsequently. The mobility factor $R_{f}$ is influenced by soil parameters, including organic matter content, $\mathrm{pH}$, and clay content. Ionic dissociation does not seem to play a role in the physicochemical behavior of the parent compounds; therefore, the $\mathrm{p} K_{\mathrm{a}}$ values characterizing acidity have not been taken into consideration, particularly because alkaline conditions (under which CLO behaves as a very weak acid with a $\mathrm{p} K_{\mathrm{a}}$ value of 11.09 at $20^{\circ} \mathrm{C}$ [35]) were not used during the elution. There is usually a negative correlation between the $R_{f}$ mobility indicator and the level of organic matter and clay content in soil, but exceptions (e.g., for prometryne) have also been reported [36]. The relative importance of soil parameters was also studied [37], and substance-specific differences in mobility have been observed between artificially commixed and field soils of the same clay content. Yet, the most convenient and therefore widely used laboratory method to assess substance mobility in soil is determination of elution profiles in soil column leaching experiments. Such a laboratory setup employs a soil column chromatography setup (as opposed to sTLC), in which experimental and eluent conditions can be better controlled.

Using our data obtained for partition of neonicotinoids between soil particles and water, we have calculated the soil organic carbon-water partitioning coefficients $\left(K_{\mathrm{oc}}\right)$ for the three soil types studied (see Table 2). As lower $K_{\mathrm{oc}}$ values, in general, correlate with higher mobility, our results indicate that TMX is 1.5-2.5-fold more mobile in soil than CLO, but both compounds belong to the highly mobile class according to Helling's classification scheme [34]. The $K_{\mathrm{oc}}$ values determined in our experiment occur to be close to those reported in the scientific literature. For CLO, $K_{\mathrm{oc}}$ values determined in clay and loam were very close to the average value reported [38], while that determined in sand was somewhat lower, yet still within the range of $K_{\mathrm{oc}}$ values reported [35]. For TMX, $K_{\mathrm{oc}}$ in sand and loam appeared to be closer to the average value reported [35], with that in clay being substantially higher, yet again much within the literature range [35].

Due to the extensive differences in the conditions under which $\mathrm{DT}_{50}$ values are reported in the scientific literature for CLO and TMX and due to the fact that CLO is a metabolite of TMX, far-reaching conclusions cannot be drawn from their comparison for the two compounds. What is clearly seen from median $\mathrm{DT}_{50}$ values both in water and soil is that CLO is substantially more stable than TMX, showing that it is a stable metabolite in soil. This is in agreement with the opinion considering TMX as a proinsecticide of CLO [39]. Moreover, as both CLO and TMX occur to be highly mobile on the basis of their elution profiles in given soil types (sandy soil), their leaching potential under certain conditions has to be taken into consideration, prompting a stronger precautionary approach in their authorization for use.

\section{Conclusion}

Environmental fate of neonicotinoids and especially their dissipation are strongly influenced by soil type, where these ingredients are applied. Their adsorption on soil strongly affects contamination rates and levels in surface water and subsequent exposure of nontarget species. Our findings showed the leaching characteristics of two neonicotinoid insecticide active ingredients, CLO and TMX, in various soil types (clay, loam, and sand). Both compounds were strongly and moderately retained by loam and clay, respectively, while they readily passed through sand, their differences in water and organic solvent solubility having the strongest effect on their behavior in sand. The results provide further evidence of the mobility of these water soluble ingredients, highlight the substantial role of soil characteristics in ingredient movement, and indicate that actual concentrations of neonicotinoids in leachates are influenced by not only the type of compound, but other factors as well. Among them the effect of soil type is of high importance, strongly influencing the levels and the time of occurrence of these compounds in the leachates.

\section{Disclosure}

The funders had no role in study design, data collection and analysis, decision to publish, or preparation of the paper.

\section{Competing Interests}

The authors declare that no competing interests exist regarding the publication of this paper.

\section{Acknowledgments}

This work was supported by project "Identification of Metabolites of Biologically Active Ingredients and Characterization 
of Their Chemical/Ecotoxicological Effects" (OTKA 112978), the Hungarian Scientific Research Fund, and received funding from projects "Investigation of Systemic Pesticides Including Their Distribution in Plants and Appearance in Guttation Liquid" (AD010, 2014-2018) and "Assessment of (Bio)chemical and Biological Main and Side-Effects of Agricultural Organic Microcontaminants" (AD006, 2013-2017) by the Hungarian Ministry of Agriculture. The authors express their thanks to the National Food Chain Safety Office for pesticide trade data and to Zsanett Gál, Klaudia Szternácsik, Judit Juracsek, and Csilla Magor for their assistance in the experiments.

\section{References}

[1] J. E. Casida and K. A. Durkin, "Neuroactive insecticides: targets, selectivity, resistance, and secondary effects," Annual Review of Entomology, vol. 58, pp. 99-117, 2013.

[2] P. Jeschke, R. Nauen, M. Schindler, and A. Elbert, "Overview of the status and global strategy for neonicotinoids," Journal of Agricultural and Food Chemistry, vol. 59, no. 7, pp. 2897-2908, 2011.

[3] Research and Markets, "Insecticides market by type, by crop type \& geography—global trends and forecasts to 2019," Study 2885646, Research and Markets, Dublin, Ireland, 2014.

[4] Markets and Markets, "Agrochemicals market by type, subtypes \& crop type-global trends \& forecast to 2020," Report Code AGI 3759, Markets and Markets, Pune, India, 2015.

[5] M. R. Douglas and J. F. Tooker, "Large-scale deployment of seed treatments has driven rapid increase in use of neonicotinoid insecticides and preemptive pest management in U.S. Field crops," Environmental Science and Technology, vol. 49, no. 8, pp. 5088-5097, 2015.

[6] D. Goulson, "An overview of the environmental risks posed by neonicotinoid insecticides," Journal of Applied Ecology, vol. 50, no. 4, pp. 977-987, 2013.

[7] N. Simon-Delso, V. Amaral-Rogers, L. P. Belzunces et al., "Systemic insecticides (neonicotinoids and fipronil): trends, uses, mode of action and metabolites," Environmental Science and Pollution Research, vol. 22, no. 1, pp. 5-34, 2015.

[8] E. Dankyi, C. Gordon, D. Carboo, and I. S. Fomsgaard, "Quantification of neonicotinoid insecticide residues in soils from cocoa plantations using a QuEChERS extraction procedure and LC-MS/MS," Science of the Total Environment, vol. 499, no. 1, pp. 276-283, 2014.

[9] The Task Force on Systemic Pesticides, "Worldwide integrated assessment of the impacts of systemic pesticides on biodiversity and ecosystems," 2015, http://www.tfsp.info/assets/WIA_2015 .pdf.

[10] M. L. Hladik and D. W. Kolpin, "First national-scale reconnaissance of neonicotinoid insecticides in streams across the USA," Environmental Chemistry, vol. 13, no. 1, pp. 12-20, 2016.

[11] R. Nauen and I. Denholm, "Resistance of insect pests to neonicotinoid insecticides: current status and future prospects," Archives of Insect Biochemistry and Physiology, vol. 58, no. 4, pp. 200-215, 2005.

[12] Z. Szendrei, E. Grafius, A. Byrne, and A. Ziegler, "Resistance to neonicotinoid insecticides in field populations of the Colorado potato beetle (Coleoptera: Chrysomelidae)," Pest Management Science, vol. 68, no. 6, pp. 941-946, 2012.
[13] Commission Implementing Regulation (EU) No 485/2013, http://eur-lex.europa.eu/LexUriServ/LexUriServ.do?uri=OJ:L: 2013:139:0012:0026:EN:PDF.

[14] S. Fryday, K. Tiede, and J. Stein, "Scientific services to support EFSA systematic reviews: lot 5 systematic literature review on the neonicotinoids (namely active substances clothianidin, thiamethoxam and imidacloprid) and the risks to bees," EFSA Supporting Publication EN-756, 2015.

[15] E. Watanabe, "Review on current analytical methods with chromatographic and nonchromatographic techniques for new generation insecticide neonicotinoid insecticides," in Advances in Integrated Pest Management, F. Perveen, Ed., pp. 481-510, InTech, 2012.

[16] T. Xu, Q. G. Xu, H. Li et al., "Strip-based immunoassay for the simultaneous detection of the neonicotinoid insecticides imidacloprid and thiamethoxam in agricultural products," Talanta, vol. 101, pp. 85-90, 2012.

[17] E. Watanabe, S. Miyake, and Y. Yogo, "Review of enzyme-linked immunosorbent assays (ELISAs) for analyses of neonicotinoid insecticides in agro-environments," Journal of Agricultural and Food Chemistry, vol. 61, no. 51, pp. 12459-12472, 2013.

[18] J. L. Vilchez, R. El-Khattabi, J. Fernández, A. González-Casado, and A. Navalón, "Determination of imidacloprid in water and soil samples by gas chromatography-mass spectrometry," Journal of Chromatography A, vol. 746, no. 2, pp. 289-294, 1996.

[19] L. M. B. Rigueira, K. L. Ribeiro, M. E. L. R. Queiroz, A. A. Neves, L. Zambolim, and R. M. Oliveira, "Determination of chlorpyrifos and thiamethoxam in potato tuber (Solanum tuberosum L.) and soil of Brazil using solid-liquid extraction with low temperature partitioning (SLE/LTP)," Journal of the Brazilian Chemical Society, vol. 24, no. 12, pp. 2042-2049, 2013.

[20] L. Li, G. Jiang, C. Liu, H. Liang, D. Sun, and W. Li, "Clothianidin dissipation in tomato and soil, and distribution in tomato peel and flesh," Food Control, vol. 25, no. 1, pp. 265-269, 2012.

[21] E. Sheng, H. Shi, L. Zhou et al., "Dual-labeled time-resolved fluoroimmunoassay for simultaneous detection of clothianidin and diniconazole in agricultural samples," Food Chemistry, vol. 192, Article ID 17818, pp. 525-530, 2016.

[22] V. Girolami, L. Mazzon, A. Squartini et al., "Translocation of neonicotinoid insecticides from coated seeds to seedling guttation drops: a novel way of intoxication for bees," Journal of Economic Entomology, vol. 102, no. 5, pp. 1808-1815, 2009.

[23] A. Tapparo, C. Giorio, M. Marzaro, D. Marton, L. Soldà, and V. Girolami, "Rapid analysis of neonicotinoid insecticides in guttation drops of corn seedlings obtained from coated seeds," Journal of Environmental Monitoring, vol. 13, no. 6, pp. 15641568, 2011.

[24] A. Tapparo, C. Giorio, L. Soldà et al., "UHPLC-DAD method for the determination of neonicotinoid insecticides in single bees and its relevance in honeybee colony loss investigations," Analytical and Bioanalytical Chemistry, vol. 405, no. 2-3, pp. 1007-1014, 2013.

[25] K. P. Yáñez, J. L. Bernal, M. J. Nozal, M. T. Martín, and J. Bernal, "Determination of seven neonicotinoid insecticides in beeswax by liquid chromatography coupled to electrospraymass spectrometry using a fused-core column," Journal of Chromatography A, vol. 1285, pp. 110-117, 2013.

[26] S. Seccia, P. Fidente, D. A. Barbini, and P. Morrica, "Multiresidue determination of nicotinoid insecticide residues in drinking water by liquid chromatography with electrospray ionization mass spectrometry," Analytica Chimica Acta, vol. 553, no. 1-2, pp. 21-26, 2005. 
[27] R. Karmakar, S. B. Singh, and G. Kulshrestha, "Water based microwave assisted extraction of thiamethoxam residues from vegetables and soil for determination by HPLC," Bulletin of Environmental Contamination and Toxicology, vol. 88, no. 2, pp. 119-123, 2012.

[28] C. Gonçalves da Rocha, F. Henrique Ramos França, and C. Andrea Lima Cardoso, "Quantification of thiamethoxam in rhizomes and leaves of the Hedychium coronarium and water and soil by high-pressure liquid chromatography," American Journal of Analytical Chemistry, vol. 3, no. 3, pp. 242-249, 2012.

[29] M. Anastassiades, S. J. Lehotay, D. Štajnbaher, and F. J. Schenck, "Fast and easy multiresidue method employing acetonitrile extraction/partitioning and 'dispersive solid-phase extraction' for the determination of pesticide residues in produce," Journal of AOAC International, vol. 86, no. 2, pp. 412-431, 2003.

[30] N. C. Toscano and F. J. Byrne, "Laboratory and field evaluations of neonicotinoid insecticides against the glassy-winged sharpshooter," in Proceedings of the Pierce's Disease Research Symposium, pp. 380-383, San Diego, Calif, USA, December 2005.

[31] A. Schaafsma, V. Limay-Rios, T. Baute, J. Smith, and Y. Xue, "Neonicotinoid insecticide residues in surface water and soil associated with commercial maize (corn) fields in Southwestern Ontario," PLoS ONE, vol. 10, no. 2, Article ID e0118139, 2015.

[32] H. M. Selim, C. Y. Jeong, and T. A. Elbana, "Transport of imidacloprid in soils: miscible displacement experiments," Soil Science, vol. 175, no. 8, pp. 375-381, 2010.

[33] S. Gupta, V. T. Gajbhiye, and R. K. Gupta, "Soil dissipation and leaching behavior of a neonicotinoid insecticide thiamethoxam," Bulletin of Environmental Contamination and Toxicology, vol. 80, no. 5, pp. 431-437, 2008.

[34] C. S. Helling and B. C. Turner, "Pesticide mobility: determination by soil thin-layer chromatography," Science, vol. 162, no. 3853, pp. 562-563, 1968.

[35] C. MacBean, Ed., The Pesticide Manual, British Crop Production Council, Brighton, UK, 16th edition, 2015.

[36] G. Chen, C. Lin, L. Chen, and H. Yang, "Effect of size-fractionation dissolved organic matter on the mobility of prometryne in soil," Chemosphere, vol. 79, no. 11, pp. 1046-1055, 2010.

[37] S.-N. Li, Y. Sun, T. Yang, and W.-G. Huangpu, "Relationship between mobility factors $\left(R_{f}\right)$ of two hydrophobic termiticides and selected field and artificial soil parameters," Science of the Total Environment, vol. 388, no. 1-3, pp. 206-213, 2007.

[38] European Commission, "Review report for the active substance clothianidin: finalised in the Standing Committee on the Food Chain and Animal Health at its meeting on 27 January 2006 in view of the inclusion of clothianidin in Annex I of Directive 91/414/EEC”, Tech. Rep. SANCO/10533/05, 2005.

[39] P. Jeschke and R. Nauen, "Thiamethoxam: a neonicotinoid precursor converted to clothianidin in insects and plants," in Proceedings of the Synthesis and Chemistry of Agrochemicals VII, J. W. Lyga and G. Theodoridis, Eds., vol. 948 of ACS Symposium Series, pp. 51-65, American Chemical Society, Washington, DC, USA, 2007.

[40] USEPA/Office of Pesticide Programs, Pesticide Fact SheetClothianidin, May 2003, http://www3.epa.gov/pesticides/chem search/reg_actions/registration/fs_PC-044309_30-May-03.pdf.

[41] FAO Specifications and Evaluations for Agricultural Pesticides, Clothianidin, Food and Agricultural Organization (FAO), Rome, Italy, 2011, http://www.fao.org/fileadmin/templates/agphome/documents/Pests_Pesticides/Specs/Clothianidin2011.pdf.
[42] FAO Specifications and Evaluations for Agricultural Pesticides, Thiamethoxam, Food and Agricultural Organization (FAO), Rome, Italy, 2014, http://www.fao.org/fileadmin/templates/agphome/documents/Pests_Pesticides/Specs/Thiamethoxam2014 .pdf. 

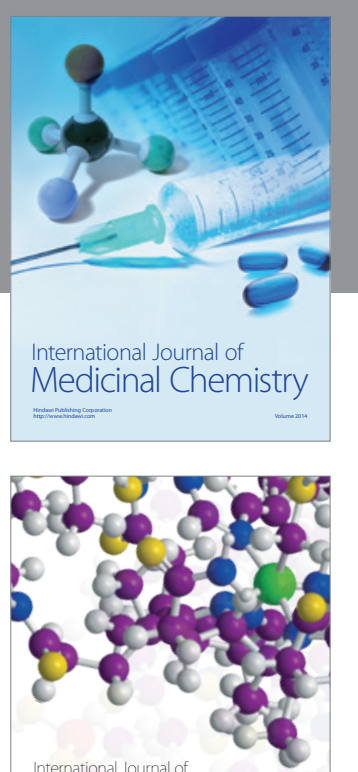

Carbohydrate Chemistry

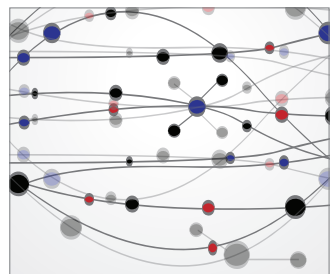

The Scientific World Journal
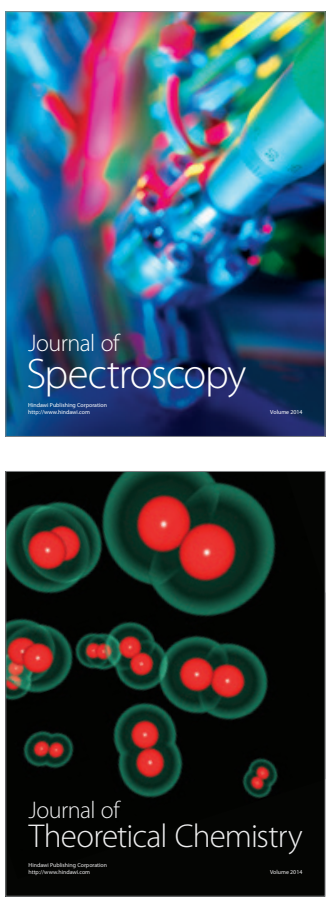
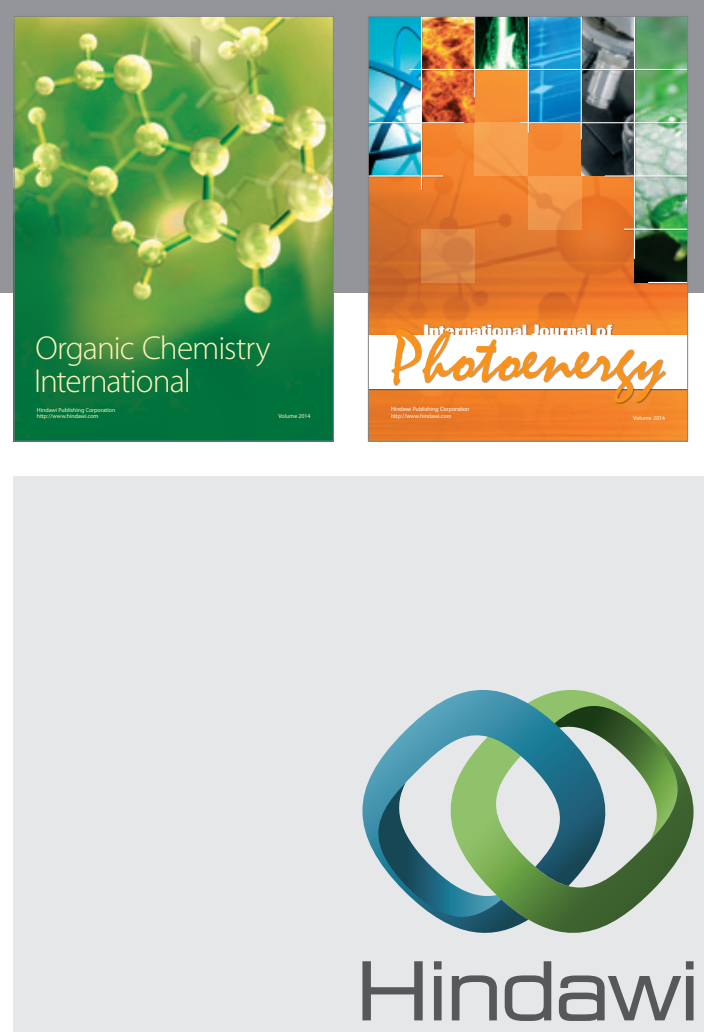

Submit your manuscripts at

http://www.hindawi.com

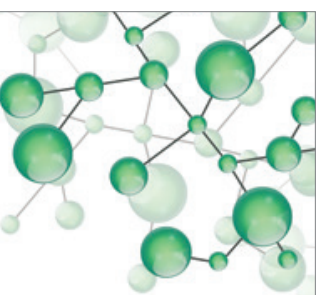

International Journal of

Inorganic Chemistry

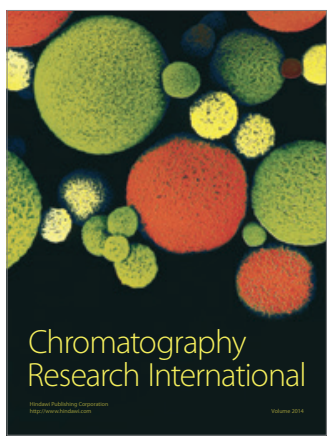

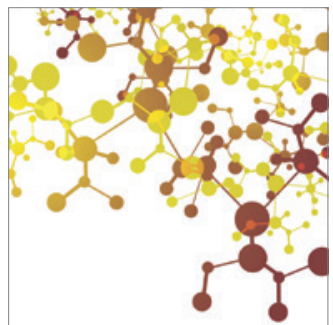

Applied Chemistry
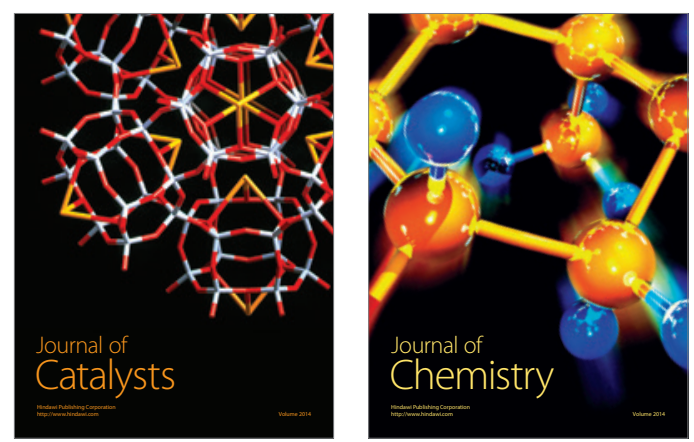
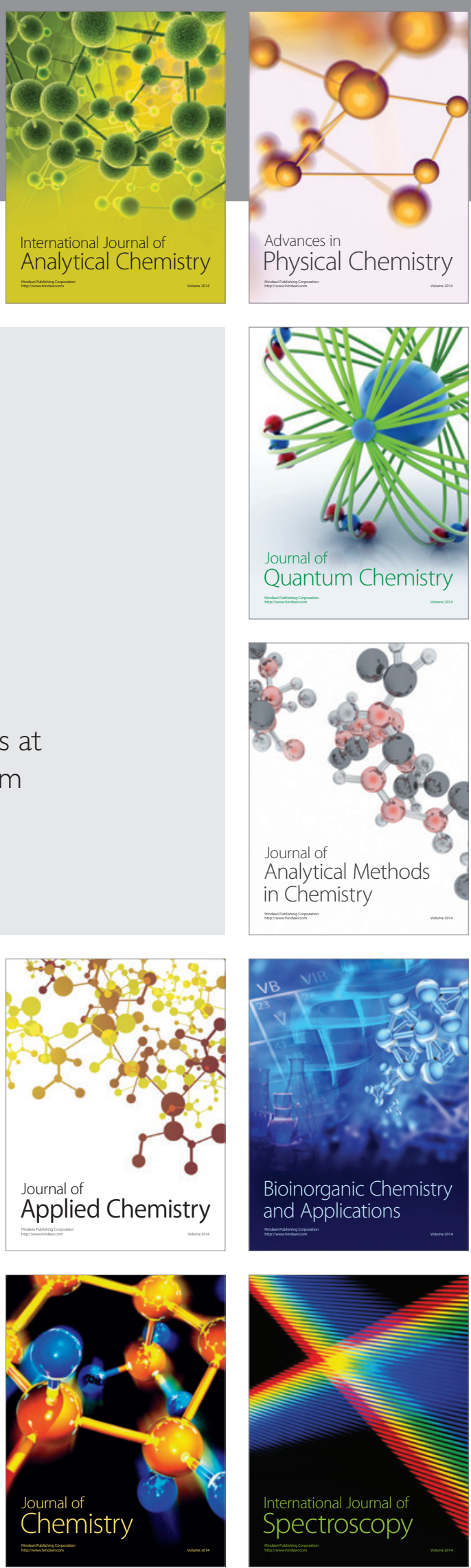